\title{
UMA REVOLUÇÃO EM PERSPECTIVA: uma análise de "Cuba en Revolución: miradas en torno a su sesenta aniversario"
}

\author{
A REVOLUTION IN PERSPECTIVE: \\ an analysis of "Cuba en Revolución: miradas en torno a su sesenta aniversario"
}

\author{
Marcos Antonio da Silva* \\ Gabriel Dourado Rocha*
}

SALAZAR, Luis Suárez (coord.). Cuba em Revolución: miradas en torno a su sesenta aniversario. Buenos Aires: CLACSO, 2019. Disponível em: http://biblioteca.clacso.edu.ar/clacso/ se/20191017033409/Cuba_en_revolucion.pdf Acesso em: 2 dez. 2019.

A Revolução Cubana é, sem dúvida, um dos acontecimentos mais emblemáticos da América Latina contemporânea e a celebração, em 2019, de seu sexagésimo aniversário foi marcada por diversas comemorações e eventos em Cuba e ao redor do planeta, demonstrando sua importância e transcendência e, principalmente, por inúmeros debates, reflexões e análises que procuraram discutir o significado, a dinâmica e os desafios atuais que caracterizam este processo.

Apesar disto e do significado histórico da Revolução Cubana para toda a região, tal discussão não teve uma repercussão adequada e aprofundada no cenário brasileiro, que continua determinado, em grande medida, por uma perspectiva eurocêntrica das ciências que conduz a um desconhecimento persistente da América Latina e dos laços que nos unem a tal região - o que Francisco de Oliveira (2006) denominou de "fronteiras invisíveis", mais sutis, profundas e eficazes que as fronteiras oficiais - e que tem sido acentuado, recentemente, pelos efeitos de uma conjuntura política polarizada e por uma onda conservadora que dificulta o debate (e a divulgação) de questões, temas e perspectivas latino-americanas e emancipatórias.

De toda forma, nos debates e reflexões que ocorreram ao redor do planeta pode-se constatar o intuito de aprofundar diversos elementos do processo revolucionário cubano considerando, dentre outros, dois aspectos fundamentais. Por um lado, procuraram compreender

\footnotetext{
* Doutor em Estudos sobre a Integração da América Latina (PROLAM/USP). Professor do curso de Ciências Sociais e do Programa de Pós-Graduação em Sociologia (PPGS) da Universidade Federal da Grande Dourados (UFGD). Membro do Laboratório Interdisciplinar de Estudos sobre América Latina (LIAL/UFGD). E-mail: marcossilva@ ufgd.edu.br

** Bacharel em Direito e mestrando do Programa de Pós-Graduação em Antropologia (PPGANT) pela Universidade Federal da Grande Dourados (UFGD). Foi membro do Laboratório Interdisciplinar de Estudos sobre a América Latina (LIAL). E-mail: gabriel_drocha@hotmail.com
} 
a natureza e o desenvolvimento de tal processo, incorporando elementos históricos que nos permitem observar os impactos, as contradições e os limites dessa onda revolucionária nas mais diversas dimensões da sociedade cubana contemporânea (arte, política, economia, demografia, cultura, educação etc.). Por outro lado, procuraram discutir a realidade contemporânea da ilha caribenha e, principalmente, a situação atual do socialismo cubano, buscando compreender e analisar suas especificidades, suas transformações e, principalmente, suas condições e desafios atuais num cenário internacional dominado pelo capitalismo financeiro, pelo consumismo excessivo, pelo hiperindividualismo e pela ampliação da desigualdade em escala global, bem como pela dificuldade de construção e afirmação de projetos alternativos viáveis, atraentes e de caráter global.

Por sua amplitude mundial, tal debate, embora tenha considerado diversas perspectivas, nem sempre, por inúmeras razões, envolveu a presença de visões e vozes de intelectuais da ilha caribenha, dificultando o desenvolvimento de visão multifacetada e aprofundada de temáticas que o envolviam. Neste sentido, esta obra preenche uma lacuna importante pois foi coordenada por Luis Suárez Salazar, um dos mais importantes intelectuais cubanos contemporâneos, e reúne trabalhos de autores cubanos e latino-americanos que conhecem profundamente a ilha e sua realidade atual e, principalmente, estão comprometidos na superação dos problemas e desafios que cercam a continuidade de tal processo, pois como afirma o organizador:

\footnotetext{
"De lo dicho se desprende que en las páginas de este volumen los lectores encontrarán diversas facetas escasamente conocidas o poco divulgadas de los logros, insuficiencias y dilemas económicos, sociales y políticos internos y externos que desde 1959 hasta la actualidad ha tenido, tiene y seguramente tendrá que enfrentar en el futuro previsible la que prefiero llamar "transición socialista cubana", así como su sexagenaria y generalmente fructífera "proyección externa", incluidos aquellos que, como se vio en el índice, se relacionan con la multifacética política exterior desplegada por los sucesivos Gobiernos revolucionarios cubanos presididos por Osvaldo Dorticós Torrado, Fidel y Raúl Castro, al igual que con la "dinámica generacional" que, desde 1959 hasta hoy, ha caracterizado a la sociedad civil y política de la Mayor de las Antillas" (SALAZAR, 2019, p. 13).
}

Além disto, a obra foi publicada pelo Conselho Latino-Americano de Ciências Sociais (Clacso), que procura impulsionar e difundir o pensamento crítico latino-americano, inaugurando a série editorial "Fóruns", que pretende publicar debates e reflexões derivadas de seus eventos, sendo este livro resultado de diversas mesas organizadas na sua oitava Conferência e no Primeiro Fórum Mundial do Pensamento Crítico, ocorrida em Buenos Aires, no final de 2018.

Da leitura da obra é possível apontar que as reflexões podem ser agrupadas em três eixos fundamentais (temas, processos e conjunturas nacionais, política externa e projeção internacional e, finalmente, fontes e lideranças políticas e intelectuais) que são introduzidos pela reflexão inicial de Gerardo Hernandez Nordelo, herói cubano que esteve detido nos EUA, 
resgatando alguns dos traços fundamentais da história da Revolução Cubana e, principalmente, discutindo as mudanças atuais que ocorrem na ilha caribenha.

O primeiro eixo se refere ao debate sobre as condições políticas, econômicas e sociais que caracterizam o socialismo cubano, analisando sua realidade interna, sua especificidade e os desafios atuais que cercam a continuidade e o aprofundamento desse processo.

Neste sentido, se destacam os trabalhos de Georgina Alfonso González, "La democracia en Cuba: algunos retos de la actualización del modelo socialista", que procura discutir como o país tem procurado desenvolver, em contraposição à visão hegemônica de democracia representativa e procedimental, um modelo de democracia participativa, popular e protagônica, que procura impulsionar os valores coletivos e solidários, em detrimento do hiperindividualismo contemporâneo, apresentando, desta forma, os pilares fundamentais do sistema político cubano contemporâneo relacionados à diversidade e à pluralidade dos atores políticos e sociais do país. Neste sentido, aponta para a emergência e o empoderamento de um sujeito popular, múltiplo e plural, em que a ampliação da participação e dos espaços decisórios será fundamental pois: "El modelo social y económico cubano socialista no podrá ser actualizado sin la participación y el Poder Popular. Diversas formas de gestión aparecen en este espacio, y pensar en alternativas de desarrollo local desde formas productivas comunitarias cooperadas es una posibilidad real" (p. 34).

Em seguida, se pode destacar o trabalho de José Luis Rodríguez Garcia, "Notas sobre la economia cubana y latino-americana: sessenta años después del triunfo de la Revolución", que apresenta uma análise instigante sobre o desenvolvimento da economia cubana, considerando os indicadores econômicos e sociais mais relevantes no período recente, e, a partir disto, desenvolve uma análise comparativa com os demais países latino-americanos (considerando indicadores como desenvolvimento, PIB, comércio exterior, políticas públicas e gastos sociais, dentre outros), demonstrando as similaridades e as diferenças entre estas e que, no caso cubano, é possível constatar que a ênfase na dimensão social (gastos e políticas sociais universais) se constitui no traço distintivo cubano em relação à região, mesmo em momentos de crise.

A partir disto, o autor aponta que qualquer balanço da economia cubana contemporânea deve levar em consideração, além da perspectiva comparativa com o contexto latino-americano, uma abordagem mais complexa e multidimensional da noção de desenvolvimento incorporando elementos geopolíticos, dentre outros, pois:

\footnotetext{
"Por un lado, contrasta la interpretación económica y social del desarrollo asumida por los revolucionarios cubanos frente a la concepción determinista y estrecha de que el desarrollo social debe estar condicionado por el crecimiento económico: visión que, de una u otra forma, ha estado presente en la forma que han evolucionado la mayoría de los países de la región. (...) La realidad es que Cuba ni ha explotado ni ha agredido a nadie en toda su história revolucionaria. En cambio, sí ha ayudado solidariamente a otros pueblos más necesitados, compartiendo no lo que le sobra, sino lo que tiene, a partir del esfuerzo y el sacrificio de sus hijos" (p. 75-76).
} 
A esses artigos podem ser incorporados o trabalho de Ramón Pihs Madruga "La transición socialista cubana: una mirada a sus dimensiones científicas y socioambientales", que discute a relação entre ciência, meio ambiente e desenvolvimento no país, destacando a implementação de um desenvolvimento sustentável, tanto social como ambiental, e as ações e adaptações do país à mudança climática global, demonstrando como tal temática foi incorporada à agenda política e econômica do país. Por fim, embora esteja na parte final do livro, pode-se incluir o trabalho de Maria Isabel Domínguez, "Las dinâmicas generacionales en Cuba: el lugar y el papel de las juventudes", que discute a dinâmica populacional da ilha, discutindo o processo de envelhecimento da população do país, acentuado pela onda migratória recente, e a transição geracional, demonstrando a necessidade de desenvolvimento de políticas públicas consistentes e do empoderamento da juventude cubana, como um elemento importante para a continuidade do processo revolucionário.

Um segundo eixo de abordagem refere-se à projeção internacional e à política externa cubana, discutindo os fundamentos, a atuação e os laços internacionais da Revolução Cubana, principalmente em relação à América Latina e sua adaptação ao novo contexto regional e internacional.

Neste sentido, destaca-se o trabalho de Isabel Allende Karam, diretora do Instituto Superior de Relações Internacionais (ISRI), intitulado "La política exterior de la Revolución cubana: una mirada a su universalidad y sus diferentes dimensiones", que realiza um balanço da política externa cubana revolucionária, discutindo os princípios e prioridades que orientaram tal política, sua condução unificada em defesa da soberania e autodeterminação, as percepções equivocadas sobre esta, destacando o caráter terceiro-mundista e latino-americano como traço fundamental, permanente e distintivo de tal política, orientada pela liderança de Fidel Castro.

A partir disto, discute os desafios atuais, internos e internacionais, que cercam a continuidade e o aprofundamento de tal política, apontando que:

\footnotetext{
"En esa dificilísima situación, muchos auguraron la desaparición de la Revolución cubana. En el plano interno la divisa esencial fue preservar la independencia y la soberanía de Cuba y proteger al máximo las principales conquistas de la Revolución y el socialismo. No obstante, los principios de la política exterior cubana se mantuvieron inalterables, pero a los esfuerzos internos habría que unir nuevas tácticas en el escenario internacional. (...) Mantener y consolidar su papel de vanguardia en la arena internacional; diversificar sus relaciones exteriores, buscar nuevas vías en el plano económico y nuevos socios comerciales. En resumen, afianzar su presencia y activismo en el mundo fueron objetivos prioritarios para la política exterior cubana" (p. 123-124).
}

Em seguida, se destaca o texto de Luis Suárez Salazar, "La proyección externa de la Revolución Cubana en América Latina y el Caribe: una aproximación en sus sesenta aniversários”, coordenador da obra, que aponta que um conjunto de fatos ou acontecimentos (a vitória da 
guerrilha, a primeira lei de reforma agrária, a campanha de alfabetização, a vitória da invasão da Bahia dos Porcos, a afirmação do caráter socialista da revolução, dentre outras) indicam uma pluralidade de datas que podem indicar vários momentos emblemáticos relacionados a múltiplos sessenta anos.

Além disto, procura discutir a projeção internacional da revolução cubana, como uma categoria analítica que permite compreender diversas dimensões da atuação internacional da política revolucionária, e analisar, a partir disto, as raízes e os laços que unem tal processo à América Latina (Nuestra América) (retomando Martí e Bolívar, dentre outros) e como tais laços foram reforçados por políticas baseadas na solidariedade e integração e se consolidam com o contexto regional recente e o processo de atualização do modelo cubano. A partir disto, conclui que:

\begin{abstract}
"Asimismo, se reiteraron los conceptos acerca de la indisoluble articulación de todas esas luchas con la unidad y la integración económica y política de ese continente que, como hemos visto a lo largo de este escrito, siempre han estado presentes en el ideario y en la praxis de la proyección externa de la Revolución Cubana en América Latina y el Caribe" (p. 170).
\end{abstract}

A estes trabalhos, podemos inserir os textos de Marco Antonio Guandásegui (hijo) "El impacto de la Revolución cubana sobre América Latina: 'Solo sabemos que lo imposible es posible"', que analisa o impacto dessa na América Latina, discutindo as condições de sua emergência, compartilhadas por toda a América Latina, e que nos permitem compreender, em seus anos iniciais, o seu impacto impressionante na região, bem como sua vigência atual, derivada do desejo de libertação nacional (ou regional) e da constituição de sociedades baseadas na solidariedade e justiça social.

Por fim, o artigo do argentino Julio Gambina denominado "Consideraciones sobre la experiencia de la Revolución cubana: una mirada desde el Sur”, que discute a relevância da experiência cubana, para se compreender as potencialidades e os limites dos processos de transformação social e, a partir disto, repensa os debates sobre a transição e o socialismo neste novo século, fundamentando-se em Mariátegui, para a mudança social diante do contexto atual e das especificidades latino-americanas.

Finalmente, é possível identificar um terceiro eixo, relacionado à influência e ao legado das principais referências intelectuais (Jose Martí) ou lideranças políticas e intelectuais de tal processo (Che Guevara e Fidel Castro), pois como indica uma das autoras:

"De manera singular, han pasado a la historia de su accionar dos de sus figuras más emblemáticas: Fidel Castro Ruz y Ernesto Che Guevara. El primero, por ser su líder indiscutible, y el segundo, por su integralidad y lealtad al proyecto de liberación nacional y social asumido por los revolucionarios cubanos" (p. 257). 
O primeiro trabalho deste eixo é o Pedro Pablo Rodríguez intitulado "Martí y la revolución del pensamento: hacia una nueva cultura", que discute a originalidade e o alcance do pensamento martiano, sua condição latino-americana em contraposição à mentalidade colonial e eurocêntrica, e seu papel como fonte fundamental do processo revolucionário e de inspiração e desenvolvimento de uma política cultural de caráter emancipatório e apropriada à Cuba e à Nuestra América.

Em seguida, emerge o artigo de Maria del Carmem Ariet García, diretora do Centro de Estudos Che Guevara, "Del pensamento y actuar del Che: validez y transcendência” que analisa a presença e a atuação do Che na construção do socialismo cubano, discute sua importância nas diferentes etapas do processo revolucionário cubano, e aponta sua concepção inovadora do marxismo, como um sistema integral e crítico de transformação social, em que se destacam a moral e a consciência social (junto à solidariedade e ao exemplo) como um elemento fundamental para tal processo.

A partir disto, a autora aponta que, vislumbrando os erros e equívocos do socialismo soviético, Che Guevara destacava a importância da consciência e do compromisso social, e indicava que:

\footnotetext{
"Ante la evidencia de esas manifestaciones negativas y la puesta en práctica de un modelo en retroceso, surgió en el Che la pregunta de lo que se debe hacer para impedirlo y sobre de qué manera actuar ante una traslación mecánica impuesta desde el modelo soviético entonces imperante. Las alternativas planteadas por él se sustentaron no solo en un pensamiento coherente, sino en la necesidad de la apropiación de una verdadera participación de todos, apoyados en una dirección que los involucre en el trabajo y en la vida cotidiana y que los eduque dando el ejemplo, y nunca por medio de decretos impositivos" (p. 272).
}

Por fim, destaca-se o texto da pesquisadora mexicana Josefina Morales, "Pensamiento y legado de una imensidad histórica: Presentación de Yo soy Fidel" que, discutindo o livro de John Saxe-Fernández (Yo soy Fidel: pensamento y legado de una imensidad histórica), apresenta e analisa os diversos depoimentos dos intelectuais que contribuíram para a obra, demonstrando a relevância e a vigência do pensamento de Fidel Castro para o desenvolvimento da Revolução Cubana.

Diante disto, pode-se apontar que a obra oferece uma reflexão instigante e atualizada sobre a realidade contemporânea de Cuba e os desafios que perpassam a continuidade ou o aprofundamento do seu processo revolucionário. Além disto, por estar fundamentada em análises, informações, dados e estatísticas atualizadas contribui para um conhecimento mais objetivo dessa realidade e, em tempos de desinformação ou manipulação de dados, também propicia ao leitor a aprendizagem de um tratamento objetivo e cuidadoso com as informações disponíveis. 
Desta forma, possibilita um balanço multidimensional do processo revolucionário cubano, indicando seus avanços, limites e desafios atuais, e contribui para uma compreensão histórica de tal processo e uma análise comparativa, principalmente em relação à América Latina, que nos permite compreender a ilha caribenha de um modo mais realista e em perspectiva.

Apesar disto, vale mencionar que, certamente, apresenta algumas limitações, boa parte delas derivadas da amplitude e complexidade de tal temática ou da dificuldade de uma análise com maior distanciamento, que pudesse refletir sobre os equívocos ou limites do processo revolucionário cubano. Neste sentido, seria importante, por exemplo, aprofundar a herança do modelo soviético nas ações e instituições sociais e governamentais e relacionar o debate sobre o processo de atualização do modelo (cubano) com os enormes desafios de reconstrução, na atualidade, do ideário socialista e dos novos projetos emancipatórios diante do capitalismo global.

Além disto, alguns aspectos importantes relacionados à sociedade cubana ou a seu processo revolucionário contemporâneo estão ausentes ou mereceriam um tratamento mais aprofundado, como a dinâmica populacional e migratória (inclusive de temáticas associadas, como gênero e relações raciais), a emergência de uma relativa desigualdade e seus efeitos, os desafios atuais das manifestações e movimentos culturais (arte, literatura, dança, música etc.) ou a análise da eficácia de diversas políticas públicas, dentre outros, e na esfera internacional um balanço mais aprofundado das relações com China e Rússia (considerando sua dimensão e efeitos) ou com os novos movimentos emancipatórios que têm emergido ao redor do planeta.

De toda forma, trata-se de uma obra fundamental para compreender a natureza e a dinâmica do processo revolucionário cubano e, principalmente, sua realidade atual, desenvolvendo um balanço sóbrio e profundo sobre os sessenta anos da Revolução Cubana, permitindo vislumbrar como parte da intelectualidade cubana e latino-americana observa e analisa as transformações que o país está vivenciando e como isso irá incidir sobre o futuro da ilha caribenha e sua relação com a região, contribuindo para a superação das "fronteiras invisíveis" que marcam a relação do Brasil com a América Latina e, particularmente, com Cuba.

\section{Referências}

OLIVEIRA, Francisco de. Fronteiras invisíveis. In: NOVAES, Adauto (org.). Oito visões da América Latina. São Paulo: Editora SENAC, 2006. p. 23-47.

SALAZAR, Luis Suárez (coord.). Cuba em Revolución: miradas en torno a su sesenta aniversario. Buenos Aires: CLACSO, 2019.

Recebido em: 16/04/2020 